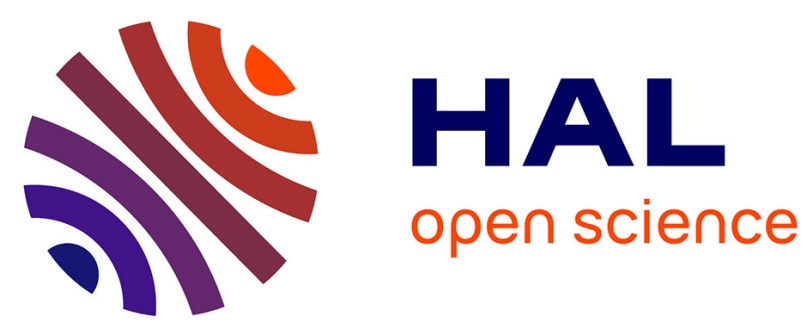

\title{
HLA class II, MICA and PRL gene polymorphisms: the common contribution to the systemic lupus erythematosus development in Czech population
}

Markéta Fojtíková, Peter Novota, Pavlína Čejková, Satu Pešičková, Dana

Tegzová, Marie Černá

\section{To cite this version:}

Markéta Fojtíková, Peter Novota, Pavlína Čejková, Satu Pešičková, Dana Tegzová, et al.. HLA class II, MICA and PRL gene polymorphisms: the common contribution to the systemic lupus erythematosus development in Czech population. Rheumatology International, 2010, 31 (9), pp.1195-1201. 10.1007/s00296-010-1431-4 . hal-00618201

\section{HAL Id: hal-00618201 \\ https://hal.science/hal-00618201}

Submitted on 1 Sep 2011

HAL is a multi-disciplinary open access archive for the deposit and dissemination of scientific research documents, whether they are published or not. The documents may come from teaching and research institutions in France or abroad, or from public or private research centers.
L'archive ouverte pluridisciplinaire HAL, est destinée au dépôt et à la diffusion de documents scientifiques de niveau recherche, publiés ou non, émanant des établissements d'enseignement et de recherche français ou étrangers, des laboratoires publics ou privés. 
HLA class II, MICA and PRL gene polymorphisms: the common contribution to the systemic lupus erythematosus development in Czech population

Authors

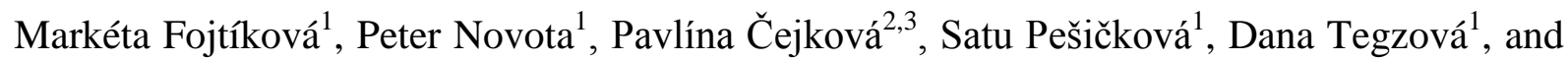
Marie Černá ${ }^{2}$

Authors' affiliation

1) Institute of Rheumatology, Na Slupi 4, 12800 Prague 2, Czech Republic

2) Department of the General Biology and Genetics, Third Faculty of Medicine, Charles University, Ruska 87, 10000 Prague 10, Czech Republic

3) Department of Anthropology and Human Genetics, Faculty of Science, Charles University Prague, Vinicna 7, 12843 Prague 2, Czech Republic

Correspondence to: MUDr. Markéta Fojtíková, Institute of Rheumatology, Na Slupi 4, Prague 128 00, Czech Republic, email: fmar@centrum.cz, tel. +420 728890 370, fax. +420 267102 650

\section{Abstract}

Objective 
The genetic components contribute to the Systemic lupus erythematosus development. This study for the first time determined the distribution of the polymorphisms and linkage disequilibrium in HLA class II, MICA and PRL gene among patients suffering from SLE and healthy Czech individuals.

\section{Patients and Methods}

DNA was obtained from the peripheral blood cells of 123 SLE patients and 96 healthy people. Allele variants of the HLA class II, MICA transmembrane polymorphism and PRL extrapituitary promoter $-1149 \mathrm{G} / \mathrm{T}$ SNP were detected using the sequence specific primers analysis, PCR-fragment analysis and PCR- RFLP, respectively.

\section{Results}

In Czech population only DRB1*03-DQB1*0201 haplotype is significantly associated with increased risk for SLE development: the frequency in SLE group was $44.7 \%$ in comparison to $15.2 \%$ in controls, $\mathrm{p}_{\mathrm{c}}<0.0001$; OR 4.54 CI 95\% (2.36-9.09). The MICA-A5.1 allele is present significantly more often in SLE (55.7\%) than controls (39.9\%), $\mathrm{p}_{\mathrm{c}}=0.005$; OR 1.88 CI 95\% (1.29-2.77) and the combination of HLA DRB1 *03 together with MICAA5.1 is strongly associated with SLE [p $p_{c}<0.000001$; OR 9.71 CI 95\% (3.4-27.7)]. On the other hand, the MICA-A6 allele is less frequent in SLE patients compared to controls, 10.6\% and $19.7 \%$ respectively $\left[\mathrm{p}_{\mathrm{c}}=0.035\right.$; OR 0.48 CI $\left.95 \%(0.28-0.82)\right]$ and the combination of absence MICA-A6 together with HLA DRB1*11 seems to be risk for SLE development compared to controls, $84.6 \%$ and $70.2 \%$ respectively, [ $\mathrm{p}_{\mathrm{c}}=0.0003$ OR 2.32 CI 95\% (1.473.70)]. We found that only $\mathrm{G}$ allele of the $-1149 \mathrm{G} / \mathrm{T}$ SNP is associated with specific clinical manifestation of SLE, arthritis $\left[\mathrm{p}_{\mathrm{c}}=0.022\right.$; OR 2.63, CI 95\% (1.45-4.81)].

\section{Conclusion}

HLA class II-MICA combinations may increase/decrease a risk for SLE development. Multiple studies focusing on the ethnical differences as well as genetic-epigenetic relationships are necessary for better understanding SLE pathogenesis.

\section{Keyword:}

Systemic lupus erythematosus, immunogenetics, gene, polymorphism 


\section{Introduction}

Systemic lupus erythematosus (SLE) is a chronic autoimmune disease which affects predominantly women in childbearing age. The pathogenesis of this illness has not been still clearly elucidated. However, complex changes during the network of the immune response may result in production of the pathogenic autoantibodies and organ damage by the immune complexes consumption [1].

Although the beginning and perpetuation of the pathological immune response may be influenced by hormonal milieu and some factors such as stress, infections and others [2,3], the genetic background for SLE development is necessary [2,4]. In fact, cooperation between multiple predisposing genetic loci determines individuals susceptible to SLE. Interestingly, SLE genome-wide studies particularly in Caucasian population demonstrated risk areas on the several chromosome, namely 1q25.1, 3p14.3, 4p16, 6p21, 7q32, 11p15.5, 16p12.3, 16p11.2 and 20p12 [5,6,7,8]. The candidate genes are mainly involved in the immune response regulation particularly in B-cell maturation [5,9], complement activation, immune cells communication [9] and expression of the intracellular transcriptional factors such as interferon regulatory factor 5 (IRF5) and signal transducer and activator of transcription 4 (STAT4) [2,9]. The highly polymorphic major histocompatibility complex (HLA) which encoded the peptides class I and II for antigen and autoantigen presentation to CD8+ T and CD4+ T cells, respectively, is located within the SLE strongly susceptible region 6p22.3-21.1 $[5,10]$. HLA alleles frequency may vary among different population [11], are in linkage disequilibrium and may be predisposing markers for various autoimmune diseases [12]. SLE has been associated with extended HLA class I and II haplotypes: B*08 - DRB1*0301DQA1*0501-DQB1*0201 and DRB1*1501-DQA*0102-DQB1*0602 [13, 14] in Caucasian population. Nevertheless, other risk genes are located near the HLA region. The major histocompatibility complex class I chain - related gene A (MICA) is located $47 \mathrm{~kb}$ centromeric to the HLA-B locus [15] and encodes MICA protein which is expressed on the keratinocytes, endothelial cells and monocytes under the stress condition [16]. MICA peptide interacts with NKG2D/DAP10 receptor of the nature killers (NK) cells and receptor of the CD8 and $\delta \gamma \mathrm{T}$ lymphocytes and stimulates Th2 immune response [17, 18, 19]. MICA consists of the three extracellular domains, transmembrane segment (TM) and cytoplasmatic tail compound 383 amino acids polypeptide. The trinucleotide microsatellite polymorphism in the exon 5 of the TM region, namely alleles MICA-A4, 5, 6, 7, 8, 9, 10 according the [GCT]n repetitions and allele MICA-A5.1 with G insertion between the second and third repetitions has been described $[20,21,22]$. The MICA 5.1 allele of this microsatellite polymorphism was 
identified as the independent risk allele for SLE development in an Italian population [23], however, next Spanish study demonstrated linkage disequilibrium between MICA 5.1 and B*08, but not with DRB1*03 [24].

In our work we investigated polymorphisms of the HLA class II, MICA and prolactin (PRL) gene in patients suffering from SLE in Czech patients with Slavic origin. PRL gene is located close to the risk SLE region. Prolactin may act as a cytokine and recent data show that PRL can break an autoreactive B-cells apoptosis and cause SLE in susceptible animals [25, 26]. In humans, elevated serum PRL levels have been associated with active SLE [27] and immune cells from SLE patients produce more PRL than those from healthy individuals. Lymphocyte PRL synthesis is regulated by alternative, extrapituitary promoter and the $G$ allele of the -1149 G/T SNP of extrapituitary PRL promoter (rs1341239) leads to higher PRL expression [28]. 


\section{Patients and methods}

Patients

123 Czech patients, $106(86.2 \%)$ women and 17 (13.8\%) men, with average age 43.4 years. All of them fulfilled at least four criteria for SLE diagnosis according to the American College of Rheumatology (ACR) classification [29].

As a control group we examined 99 healthy Czech individuals, 29 (29.3\%) women and 70 (70.7) men, with average age 39.3 years.

This study was approved by the Ethical Committee of the Third Faculty of Medicine, Charles University in Prague.

Methods

Genomic DNA preparation: DNA was extracted from peripheral leucocytes by commercial set QiaAmp DNA Maxi Kit spin columns (QIAGEN GmbH, Hilde, Germany). DNA was diluted to the concentration $30 \mathrm{ng} / \mathrm{ul}$.

HLA- class II typing was performed using polymerase chain reaction (PCR) with sequence specific primers (SSP-PCR). For genotyping HLA class II region was used the Olerup SSP $\mathrm{SP}^{\mathrm{TM}}$ HLA-DRB1 and HLA-DQB low resolution kit and HLA-DQB1 high resolution subtyping kit for each detected allele (Genovision, Oslo, Norway). Procedure of PCR mix amplification and PCR cycling parameters was in concordance with recommendations. The PCR products were identified on $2 \%$ agarose gel.

MICA exon 5 transmembrane microsatellite polymorphism analysis was completely depicted by Novota et al. [30]. The following primers were used for the polymorphic transmembrane region: forward Cy5-5'- GCTGGTCTTCAGAGTCATTGGC-3' and reverse 5'-GGACCCTCTGCAGCTGATGTTTTC-3'. The PCR products were identified using electrophoretic separation in the ALFexpress II DNA analysis system and the fragment sizes were determined automatically using the Fragment analyzer v 1.02 software (Amersham Biosciences, Vienna, Austria). According to fragment sizes, 123bp, 126bp, 127bp, 129 bp and 139 bp we identified MICA A4, A5, A5.1, A6 and A9 alleles, respectively.

-1149 G/T SNP extrapituitary PRL promoter was detected using PCR-RFLP methodology previously described [31]. Briefly, the 137 base pairs (bp) region of the PRL extrapituitary promoter was amplified by employing the following primers: forward 5'GCAGGTCAAGATAACCTGGA and reverse 5'-CATCTCAGAGTTGAATTTATTTCCTT. ApoI restriction endonuclease for RFLP was used, the restriction fragments were visualized on $4 \%$ agarose gel. We identified these genotypes: TT homozygote characterized by $120 \mathrm{bp}+$ 
17 bp, GG homozygote by 85 bp +35 bp +17 bp, and GT heterozygote by 120 bp +85 bp + 35 bp +17 bp DNA fragments.

Statistical analysis:

Allele and genotype frequencies were calculated using standard methods and statistical evaluation Epi Info software (Version 3.3 October 2004, Atlanta, Georgia). Statistical differences in allele distributions were analyzed by either a 2 or Fischer's exact probability test. Significance was defined using a Bonferroni corrected $\mathrm{P}$ value lower than 0.05 . The strength of the associations observed was estimated by calculating the odds ratios (OR) according to Wolf's method with a Haldane's correction. 


\section{Results}

HLA class II genotyping: Allele frequencies and genotype distribution

Distribution of the HLA class II alleles was investigated in 222 individuals, 123 SLE patients and 99 healthy volunteers, all of them were Czechs origin. There were significant differences in HLA DRB1 and HLA DQB1 allele distribution between patients and controls, $p<0.001$ and $p=0.0048$ using $\chi^{2}$ test respectively. We found that frequencies for four alleles in each HLA class II subgroup in our healthy population differ from SLE patients: HLA DRB1*03, *08, *15 and *11 (see Table 1) and HLA DQB1*0201,*0402,*0602 and *0301 (see Table 2).

The higher frequency of the HLA DRB $1 * 03, * 08$ and $* 15$ alleles was detected in SLE group, $22.8 \%, 6.1 \%$ and $22.0 \%$ respectively, compare to healthy controls $10.6 \%, 2.0 \%$ and $14.7 \%$ respectively. However, only differences in HLA DRB $1 * 03$ allele frequency maintain the statistical significance after corrections, $\mathrm{p}_{\mathrm{c}}=0.008$; OR $2.5 \mathrm{CI} 95 \%$ (1.44-4.27). On the other hand, we found lower frequency of HLA DRB1*11 allele in SLE patients $(6.1 \%$ versus $13.6 \%$ in controls), but $\mathrm{p}$ value lost significance after corrections.

We found an association between HLA DQB1*0201 and SLE, which was detected in $22.8 \%$ SLE patients compared to $10.6 \%$ in controls, $\mathrm{p}_{\mathrm{c}}=0.01$; OR 2.5 CI 95\% (1.44-4.34). In our SLE patients group, neither higher frequencies of the HLA DQB1*0402 and HLA DQB1*0602 alleles $(5.3 \%$ and $21.1 \%$ compared to $1.5 \%$ and $13.1 \%$ in general population, respectively) nor the lower frequency HLA DQB1*0301 (8.5\% versus $17.2 \%$ in controls) did reach statistical significance after corrections.

We identified 52 genotypes of HLA DRB1 and 48 genotypes of HLA DQB genes. We did find neither deviation between studied groups and HLA DRB1 or HLA DQB1 genotypes nor any significant association between homo or heterozygotes and SLE (data not shown).

The strong linkage disequilibrium between HLA DRB1*03 -DQB1*0201, HLA DRB1*08 - DQB1*0402, HLA DRB1*15 -DQB1*0602 and HLA DRB1*11 - DQB1*0301 $\left(p=10^{-5} ; p=0.03 ; p=10^{-9} ; p=10^{-6}\right.$ respectively) was defined in the control group. We confirm as a main HLA predisposition factor HLA DRB $1 * 03$ allele $\left(\mathrm{p}_{\mathrm{c}}=0.008\right)$. Significant association with HLA DQB1*0201 $\left(\mathrm{p}_{\mathrm{c}}=0.01\right)$ is due to known linkage disequilibrium.

MICA transmembrane microsatellite polymorphism exon 5 analysis

We detected five alleles of the MICA TM exon 5 microsatellite polymorphism, A4, A5, A5.1, A6 and A9 in both, SLE patients and control group (see Table 3). There was a significant difference of allele distribution between this two groups, $\mathrm{p}<0.01$ ( $\chi^{2}$ test). We found that MICA-A5.1 allele is present significantly more often in SLE patients (55.7\%) than 
controls $(39.9 \%), \mathrm{p}_{\mathrm{c}}=0.005$; OR 1.88 CI 95\% (1.29-2.77). Furthermore, the allele MICA-A6 is less frequent in SLE patients compared to controls, $10.6 \%$ and $19.7 \%$ respectively, $\mathrm{p}_{\mathrm{c}}=$ 0.035; OR 0.48 CI 95\% (0.28-0.82).

Conversely, there were no differences in genotypes distribution of MICA TM exon 5 microsatellite polymorphism, which we detected 15 in each group (data not shown). Although, we didn't ascertain any significant association, there was a trend to higher presence of MICA-A5.1/A5.1 homozygotes among SLE patients compared to controls, $31.7 \%$ and $20.2 \%$ respectively $\left(\mathrm{p}_{\mathrm{u}}=0.05\right.$; OR 1.85 before correction) and lower presence of MICA-A4/A6 heterozygotes in SLE patients $(1.6 \%)$ than in control subjects $(10.1 \%)\left(\mathrm{p}_{\mathrm{u}}=0.005\right.$; OR 0.14 before correction).

In the control group we tested linkage disequilibrium between HLA class II (DRB1*03, *04, *11,*15) and MICA-A4, A5, 5.1, A6 and A9. We did not find any linkage disequilibrium between HLA DRB and MICA alleles, $p>0.05$ in all cases.

\section{Contribution of MICA-A5.1 and MICA-A6 to susceptibility to SLE}

We also tested if the risk alleles HLA DRB $1 * 03, * 08, * 15$ and MICA-A5.1, and the protective alleles HLA DRB1 *11 and MICA-A.6, respectively, contribute to the disease development independently.

HLA DRB1 *03 allele together with MICA-A5.1 allele was strongly associated with SLE compared to controls, $16.7 \%$ to $2.0 \%$ respectively $\left[p_{c}<0.000001\right.$; OR $9.71(3.4-27.7)$ ] and the number of double negative subjects was significantly reduced in SLE group in comparison with control one, $38.2 \%$ and $51.5 \%$ respectively, $\mathrm{p}_{\mathrm{c}}=0.005$; OR $0.58(0.39-0.85)$. However, there were no differences in the number of combination of HLA DRB1*03 positive and negative, and ad vice versa MICA-A5.1 in SLE and controls group.

In the case of HLA DRB $1 * 08$ and $* 15$ alleles, we found that the MICA-A5.1 allele occurs more frequently in SLE negative for DRB1*08 (52.4\%) and DRB1*15 (43.5\%) than in controls 38.9\% [ $\mathrm{p}_{\mathrm{c}}=0.004$; OR $\left.1.75(1.19-2.56)\right]$ and $31.3 \%$ [ $\mathrm{p}_{\mathrm{c}}=0.008$; OR 1.69 (1.14-2.5)], respectively and in SLE group was significantly reduced the number of negative subjects for both DRB1 *08 and MICA-A5.1 (41.5\%) and DRB1 *15 and MICA-A5.1 (34.5) compared to controls, 59.1\% [ $\mathrm{p}_{\mathrm{c}}=0.0002$; OR $\left.0.49(0.33-0.71)\right]$ and 52.5\% $\left[\mathrm{p}_{\mathrm{c}}=0.0001\right.$; OR $0.48(0.32-$ 0.70)] respectively.

The absence of HLA DRB1*11 together with MICA-A6 allele is significantly more common in SLE compared to controls, $84.6 \%$ and $70.2 \%$ respectively, [ $\mathrm{p}_{\mathrm{c}}=0.0003$ OR 2.32 (1.47-3.70)].

\section{$\underline{-1149 \mathrm{G} / \mathrm{T} \text { PRL extrapituitary promoter polymorphism analysis }}$}


We did not detect any association between alleles of the -1149 G/T SNP extrapituitary PRL promoter in SLE patients and healthy individuals (Table 3) and no differences in genotypes distribution between groups were observed (data not shown).

Moreover, we did not find any linkage disequilibrium between $\mathrm{G}$ or $\mathrm{T}$ allele and HLA class II alleles $(\mathrm{DRB} 1 * 03, * 08, * 11, * 15), \mathrm{p}>0.05$ in all cases.

Analysis of risk and protective SLE haplotypes

In our population we found that only DRB1*03-DQB1*0201 haplotype is significantly associated with increased risk for SLE development: the frequency in SLE group was 44.7\% versus $15.2 \%$ in controls, $\mathrm{p}_{\mathrm{c}}<0.0001$; OR 4.54 (2.36-9.09). The other risk haplotypes, DRB $1 * 08-D Q B 1 * 0402$ [10.6\% (SLE) vs. 3.0\% (controls), $\mathrm{p}_{\mathrm{u}}=0.03$; OR 3.84] and DRB1*15DQB1*0602 (42.3\% vs. $25.3 \%, \mathrm{p}_{\mathrm{u}}=0.008$; OR 2.17) as well as protective one, DRB1*11$\mathrm{DQB} 1 * 0301\left[12.2 \%\right.$ (SLE) vs. $24.2 \%$ (controls), $\mathrm{p}_{\mathrm{u}}=0.01$; OR 0.43$]$, didn't reach statistical significance after corrections.

When we looked for the risk/protective HLA haplotypes extended with MICA and PRL alleles we did not find any significant differences between SLE and controls. However, we noticed a trend: the haplotype DRB1*03-DQB1*0201-MICA-A5.1 was more common in SLE patients $72.7 \%$ than in controls $20.0 \%, \mathrm{p}_{\mathrm{u}}=0.002$ (OR 11.11), but the combination of DRB1*03-DQB1*0201 and MICA-A4 and MICA-A6 seems to occur rarely in SLE than healthy subjects, $5.5 \%$ and $33.3 \%, \mathrm{p}_{\mathrm{u}}=0.002(\mathrm{OR} 0.12)$ and $1.8 \%$ and $33.3 \%, \mathrm{p}_{\mathrm{u}}=0.001(\mathrm{OR}$ $0.04)$, respectively.

\section{Correlation between the clinical and laboratory findings in SLE and predisposing alleles}

We divided our SLE patients according to the presence or absence of the specific organ involvement (according to the SLE classification criteria: kidney, CNS, heart, lungs, joints, skin and blood cells) and the autoantibodies (antids-DNA, anti-Sm, anti-Ro, anti-La). We compared the allele frequencies in patients with organ manifestation or autoantibodies versus patients without these signs. We found that G allele of the $-1149 \mathrm{G} / \mathrm{T}$ SNP of the extrapituitary PRL promoter is significantly associated with joint involvement in SLE $(63.3 \%)$ compared to SLE patients without this manifestation $(39.6 \%), \mathrm{p}_{\mathrm{c}}=0.022$; OR 2.63, CI (95\%) 1.45-4.81. In all other cases detected risk alleles did not reach significance after corrections.

\section{Discussion}

SLE is a multifactorial disease and for this reason both genetic and environmental factors are contributing to its manifestation. In our work we studied polymorphisms in three 
genes (HLA class II, MICA, PRL) located within the susceptible locus for SLE on the chromosome $6[11,23,28]$. Genes in this region show a high level of polymorphism and linkage disequilibrium. All three genes, that we studied, encoded molecules influenced in the immune response. HLA class II glycoproteins are responsible for initial step of the immune response and antigen presentation, stress-inducible MICA peptides may contribute to the Th2 immune reaction and induction of tolerance [17, 18]. Prolactin like a cytokine modulates immune cells ( $\mathrm{T}$ and dendritic cells) maturation and differentiation $[32,33]$ and has direct effect to autoreactive B cells development [26].

The immunogenetic study focusing on the SLE development in Czech population has not been performed before. The HLA allele frequencies are slightly different in central European population than in other European countries [34].

In our work we detected a strong association between SLE and HLA DRB $1 * 03$, HLA DQB1*0201 alleles, as it was demonstrated previously in the other Caucasian population [10, 14, 24, 35]. Similarly we found significantly increased HLA DRB1*03-DQB1*0201 haplotype in our SLE patients. On the other hand, the association between the haplotype DRB1*1501 - DQB1*0602 and both DRB1*15 and DQB1*0602 alleles did not reach statistical significance after corrections. Although several studies show the association of the DRB1*1501 -DQB1*0602 and SLE [14, 36], our finding is in concordance with Smerdel and col. who demonstrated only weakly elevation of DRB1*15 allele in SLE patients [35]. Interestingly, we found a protective role of HLA DRB $1 * 11$, this association has not been described before. On the other hand, the DRB $1 * 07$ allele which is supposed to be protective $[13,36]$ was not decreased in our population. This allele may vary among populations, for example the work from neighboring country Poland, demonstrated higher frequency of this allele in a small cohort [37].

The next point of our study was to elucidate the role of MICA TM microsatellite polymorphism in SLE development. In concordance with the Italian and Spanish [23, 24] previously published works, we detected high frequencies of the MICA-A5.1 allele in SLE patients. Like others we did not find a linkage disequilibrium between MICA-A5.1 and HLA DRB1 alleles, especially *03. However, the presence of the MICA-A5.1 allele positively modifies genetic risk of HLA DRB $1 * 03$ to SLE. Similarly, Lopez-Vazquez demonstrated independent risk of MICA-A5.1 allele to the HLA DRB1*03-DQB1*0201 haplotype leading to another autoimmune disease, celiac disease in adults [38]. Completely different interaction is between MICA-A5.1 allele and HLA DRB1*08/HLA DRB1*15. In the case of HLA DRB1 $* 08$ and $* 15$ alleles, we found that the MICA-A5.1 allele occurs more frequently in SLE 
negative for DRB1*08 and DRB1*15 than in controls. Moreover, negativity for MICA-A5.1 allele together with absence of HLA DRB $1 * 08$ and DRB1*15 reduces the risk for SLE development. We can conclude according to the Svejgaard and Ryder [39], that DRB1 *08 or *15, and MICA-A5.1 themselves are independent predisposition factors (OR 3.3 or 1.6, and OR 1.9, respectively), MICA-A5.1 doesn't increase the risk for SLE development with these alleles, however it may play some opposite role in triggering of autoimmune reaction and for this reason presence of MICA-A5.1 in SLE ethiopathogenesis excludes function of DRB $1 * 08$ or $* 15$ alleles. However, in our study we identified only uncorrected significance for these HLA alleles and further studies with increased number of SLE patients and different populations are required to confirm this finding. The new outcome of this work is observation of the lower frequency of MICA-A6 allele in SLE patients, moreover, the combination of the absence of two alleles, HLA DRB1*11 and MICA-A6 may lead to higher susceptibility to develop SLE. Gambelunghe and col. found that MICA-A9 is a protective allele, but we didn't confirm it [23]. This discrepancy may be due to the different characteristics of patients, for example, in our study the MICA-A9 allele is higher in SLE patients with skin involvement, $16.6 \%$ compared to those without this manifestation $7.7 \%$ (insignificant observation, data not shown). On the other hand, MICA-A5 allele is the risk allele in Italian study, but in Spanish one seems to be protective [23, 24]. In our work we didn't find any association between MICA-A5 allele and SLE itself or any clinical or lab characteristic. It is also necessary to keep in mind that there is huge variability in MICA allele frequencies among populations probably due to microsatellite type of polymorphism [22].

In conclusion, we detected a strong association of the HLA DRB1*03- DQB1*0201 with SLE, that is positively modified by MICA-A5.1 in the Czech, central European population. MICA exon 5 transmembrane gene microsatellite polymorphism varies among European population. This is the first work of this region about immunogenetic background of the Czech SLE patients.

\section{Acknowledgement}

This study was supported by the Czech Ministry of Health-Research Project MZO 00023728 and the MHCR grant NS/10618-3. 


\section{Literature}

1. Mok CC, Lau CS (2003) Pathogenesis of systemic lupus erythematosus. J Clin Pathol 56: $481-490$

2. Molokhia M, McKeigue P (2006) Systemic lupus erythematosus: genes versus environment in high risk populations. Lupus 15: 827-832

3. Petri M. (2008) Sex hormones and systemic lupus erythematosus. Lupus 17: 412-415

4. Castro J, Balada E, Ordi-Ros J, Vilardell-Tarres M (2008) The complex immunogenetic basis of systemic lupus erythematosus. Autoimmun Rev 7: 345-351

5. International Consortium for Systemic Lupus Erythematosus Genetics (SLEGEN), Halley JB, Alarcon-Riquelme ME, Criswell LA, Jacob CO, Kimberly RP, Moser KL et al. (2008) Genome-wide association scan in women with systemic lupus erythematosus identifies susceptibility variants in ITGAM, PXK, KIAA1542 and other loci. Nat Genet 40: 204-210

6. Lee YH, Nath SK (2005) Systemic lupus erythematosus susceptibility loci defined by genome scan meta-analysis. Hum Genet 118: 434-443

7. Cervino AC, Tsinoremas NF, Hoffman RW (2007) A genome-wide study of lupus: preliminary analysis and data release. Ann N Y Acad Sci 1110: 131-139

8. Rhodes B, Vyse TJ (2008). The genetics of SLE: an update in the light of genome-wide association studies. Rheumatology (Oxford) 47: 1603-1611

9. Hom G, Graham RR, Modrek B, Taylor KE, Ortmann W, Garnier S, Lee AT, Ferreira RC, et al. (2008) Association of systemic lupus erythematosus with C8orf13-BLK and ITGAMITGAX. N Engl J Med 358: 900-909

10. Tsao BP (2004) Update on human systemic lupus erythematosus genetics. Curr Opin Rheumatol 16: 513-521

11. Nowak J, Mika-Witkowska R, Polak M, Zajko M, Rogatko-Koros M, Graczyk-Pol E, Lange A. (2008) Allele and extended haplotype polymorphism of HLA-A,-C,-B,-DRB1 and DQB1 loci in Polish population and genetic affinities to other populations. Tissue antigens 71: 193-205

12. Yu CC, Whitacre CC (2004) Sex, MHC and complement C4 in autoimmune diseases. Trends Immunol 25: 694-699

13. Gladman DD, Urowitz MB, Darlington GA (1999) Disease expression and class II HLA antigens in systemic lupus erythematosus. Lupus 8: 466-470

14. Graham RR, Ortmann WA, Langefeld CD, Jawaheer D, Selby SA, Rodine PR, Baechler EC, et al. (2002) Visualizing human leukocyte antigen class II risk haplotypes in human systemic lupus erythematosus. Am J Hum Genet 71: 543-553 
15. Bahram S, Bresnahan M, Gerahty DE, Spies T (1994) A second lineage of mammalian major histocompatibility complex class I genes. Proc Natl Acad Sci USA 91: 6259-6963

16. Zwirner NW, Fernandez-Vina MA, Stastny P (1998) MICA, a new polymorphic HLArelated antigen, is expressed mainly by keratinocytes, endothelial cells, and monocytes. Immunogenetics 47: 139-48

17. Zhang Y, Stastny P (2006) MICA antigens stimulate T cell proliferation and cell-mediated cytotoxicity. Hum Immunol 67: 215-222

18. Cerwenka A (2009) The new list on the regulation of NKG2D ligand expression. J Exp Med 206: 265-268

19. Groh V, Steine A, Bauer S, Spies T (1998) Recognition of stress-induced MHC molecules by intestinal epithelial gammadelta T cells. Science 279: 1737-1740

20. Rueda B, Pascual M, Lopez-Nevot MA, Gonzales E, Martin J (2002) A new allele within the transmembrane region of the human MICA gene with seven GCT repeats. Tissue Antigens 60: 526-528

21. Gambelunghe G, Brozzeti AL, Ghaderi M, Tortoioli C, Falorni A (2006) MICA A8: a new allele within MHC class I chain-related A transmembrane region with eight GCT repeats. Hum Immunol 67: 1005-1007

22. Ota M, Katsuyama Y, Mizuji N, Ando H, Furihata K, Ono S, Pivetti-Pezzi P, Tabbara KF, Palimeris GD, Niobin B, Davatchi F, Chams H, Geng Z, Bahram S, Inoko H (1997) Trinucleotide repeat polymorphism within exon 5 of the MICA gene (MHC class I chainrelated gene A): allele frequency in the nine population groups Japanese, Northern Han, Hui, Uygur, Kazakhstan, Iranian, Saudi Arabian, Greek and Italian. Tissue Antigens 49: 448-454

23. Gambelunghe G, Gerli R, Bartoloni Bocci E, Del Sindaco P, Ghaderi M, Sanjeevi CB, Bistoni V, Falorni A (2005) Contribution of MHC class I chain-related A (MICA) gene polymorphism to genetic susceptibility for systemic lupus erythematosus. Rheumatology 44: 287-292

24. Sanchez E, Torres B, Vilches JR, Lopez-Nevot MA, Ortego-Centeno N, Jimenez-Alonso J, Gonzalez-Gay MA, Ramon E, Sanchez-Roman J, Nunez-Roldan A, Martin J, GonzalezEscribano MF (2006) No primary association of MICA polymorphism with systemic lupus erythematosus. Rheumatology 45: 1096-1100

25. Cohen-Solal JF, Jeganathan V, Hill L, Kawabata D, Rodriguez-Pinto D, Grimaldi C, Diamond B (2008) Hormonal regulation of B-cell function and systemic lupus erythematosus. Lupus 17: 528-532 
26. Saha S, Gonzalez J, Rosenfeld G, Keiser H, Peeva E (2009) Prolactin alter the mechasnism of B cell tolerance induction. Arthritis Rheum 60: 1743-52

27. Leanos-Miranda A, Cardenas-Mondragon G (2006) Serum free prolactin concentrations in patients with systemic lupus erythematosus are associated with lupus activity. Rheumatology 45: $97-101$

28. Stevens A, Ray D, Alansari A, Hajeer A, Thomson W, Donn R, Ollier WE, Worthington J, Davis JR (2001) Characterization of a prolactin gene polymorphism and its associations with systemic lupus erythematosus. Arthritis Rheum 44: 2358-2366

29. Hochberg MC (1997) Updating the American College of Rheumatology revised criteria for the classification of systemic lupus erythematosus. Arthritis Rheum 40: 1725

30. Novota P, Kolesa L, Slavcev A, Cerna M (2004) Fluorescence-based automated fragment analysis of microsatellite polymorphism within the transmembrane region of the MICA-A gene. Folia Biologica (Praha) 50: 21-3

31. Fojtikova M, Cerna M, Cejkova P, Ruzickova S, Dostal C (2007) Extrapituitary prolactin promoter polymorphism in Czech patients with systemic lupus erythematosus and rheumatoid arthritis. Ann Rheum Dis 66: 706-707

32. Dimitrov S, Lange T, Fehm HL, Born J (2004) A regulatory role of prolactin, growth hormone and corticosteroids for human T-cell production of cytokines. Brain Behav Immun 18: $368-274$

33. Jara LJ, Benitez G, Medina G (2008) Prolactin, dendritic cells, and systemic lupus erythematosus. Autoimmun Rev 7: 251-255

34. Mack SJ, Tu B, Lazaro A, Yang R, Lancaster AK, et al. (2009) HLA-A,-B, -C, and DRB1 allele and haplotype frequencies distinguish Eastern European Americans from the general European American population. Tissue Antigens 73: 17-32

35. Smerdel-Ramoya A, Finholt C, Lilleby V, Gilboe IM, Harbo HF, Maslinski S, Forre O, Thorsby E, Lie BA (2005) Systemic lupus erythematosus and extended major histocompatibility complex - evidence for several predisposing loci. Rheumatology 44: 13681373

36. Alarcon GS, McGwin G, Bartolucci AA, Roseman J, Lisse J, Fessler BJ, Bastian HM, Friedman AW, Reveille JD (2001) Systemic lupus erythematosus in three ethnic groups. Differences in damage accrual. Arthritis Rheum 44: 2797-2806

37. Hrycek A, Siekiera U, Cieslik P, Szkrobka W (2005) HLA-DRB1 and-DQB1 alleles and gene polymorphisms of selected cytokines in systemic lupus erythematosus. Rheumatol Int 26: $1-6$ 
38. Lopez-Vazquez A, Rodrigo L, Fuentes D, Riestra S, Bousono C, Garcia-Fernandez S, Martinez-Borra J, Gonzalez S, Lopez-Larrea C (2002) MHC class I chain related gene A (MICA) modulates the development of coeliac disease in patients with the high risk heterodimer DQA1*0501/DQB1*0201. Gut 50: 336-340

39. Svejgaard A, Ryder LP (1994) HLA and disease associations: detecting the strongest association. Tissue antigens 43: 18-27 
Tables

1 .

Allele frequencies of the HLA class II among patients with Systemic Lupus Erythematosus (SLE) and healthy Czech individuals (Controls)

\begin{tabular}{|c|c|c|c|c|}
\hline $\begin{array}{c}\text { HLA } \\
\text { DRB1 } \\
\end{array}$ & $\begin{array}{c}\text { SLE } \\
2 \mathrm{n}=246(\%)\end{array}$ & $\begin{array}{c}\text { Controls } \\
2 \mathrm{n}=198(\%)\end{array}$ & Pc. & OR $(95 \% \mathrm{CI})$ \\
\hline$* 01$ & $18(7.3)$ & $20(10.1)$ & $\mathrm{ns}$ & \\
\hline *03 & $56(22.8)$ & $21(10.6)$ & 0.008 & $2.5(1.44-4.27)$ \\
\hline *04 & $25(10.2)$ & $28(14.2)$ & ns & \\
\hline$* 07$ & $32(13.0)$ & $29(14.7)$ & ns & \\
\hline$* 08$ & $15(6.1)$ & $4(2.0)$ & ns/Puc. 0.03 & $3.3(1.10-10.01)$ \\
\hline *10 & $1(0.4)$ & $2(1.0)$ & ns & \\
\hline$* 11$ & $15(6.1)$ & $27(13.6)$ & ns/Puc.0.007 & $0.4(0.21-0.82)$ \\
\hline$* 12$ & $1(0.4)$ & $2(1.0)$ & ns & \\
\hline$* 13$ & $21(8.5)$ & $24(12.1)$ & $\mathrm{ns}$ & \\
\hline$* 14$ & $5(2.0)$ & $8(4.0)$ & ns & \\
\hline$* 15$ & $54(22.0)$ & $29(14.7)$ & ns/Puc. 0.04 & $1.6(1.01-3.33)$ \\
\hline$* 16$ & $3(1.2)$ & $4(2.0)$ & ns & \\
\hline
\end{tabular}

Appendix: P value was determined by $\chi^{2}$ test comparing SLE group to controls, Puc. $=$ uncorrected $\mathrm{Pc} .=$ corrected with Bonferroni correction for 12 detected alleles, $\mathrm{n}=$ number of cases, $\mathrm{OR}=$ odds ratio, $\mathrm{CI}=95 \%$ confidence interval 

Allele frequencies of the HLA class II among patients with Systemic Lupus
Erythematosus (SLE) and healthy Czech individuals (Controls)

\begin{tabular}{|c|c|c|c|c|}
\hline $\begin{array}{c}\text { HLA } \\
\text { DQB1 }\end{array}$ & $\begin{array}{c}\text { SLE } \\
2 n=246(\%)\end{array}$ & $\begin{array}{c}\text { Controls } \\
2 \mathrm{n}=198(\%)\end{array}$ & Pc. & OR $(95 \% \mathrm{CI})$ \\
\hline$* 0201$ & $56(22.8)$ & $21(10.6)$ & 0.01 & $2.5(1.44-4.34)$ \\
\hline *0202 & $23(9.4)$ & $23(11.7)$ & ns & \\
\hline$* 0203$ & 0 & $1(0.5)$ & ns & \\
\hline$* 0301$ & $21(8.5)$ & $34(17.2)$ & ns/Puc.0.006 & $0.45(0.25-0.81)$ \\
\hline *0302 & $21(8.5)$ & $27(13.7)$ & ns & \\
\hline$* 0303$ & $9(3.7)$ & $7(3.5)$ & ns & \\
\hline$* 0304$ & $2(0.8)$ & $1(0.5)$ & ns & \\
\hline$* 0401$ & $1(0.4)$ & 0 & ns & \\
\hline$* 0402$ & $13(5.3)$ & $3(1.5)$ & ns/Puc.0.03 & $3.7(1.02-14.28)$ \\
\hline$* 0501$ & $18(7.3)$ & $20(10.1)$ & ns & \\
\hline$* 0502$ & $4(1.6)$ & $5(2.5)$ & ns & \\
\hline$* 0503$ & $5(2.1)$ & $9(4.5)$ & ns & \\
\hline$* 0504$ & $1(0.4)$ & 0 & ns & \\
\hline$* 0601$ & $2(0.8)$ & $2(1.0)$ & ns & \\
\hline$* 0602$ & $52(21.1)$ & $26(13.1)$ & ns/Puc.0.02 & $1.78(1.06-3.03)$ \\
\hline$* 0603$ & $14(5.7)$ & $14(7.1)$ & ns & \\
\hline$* 0604$ & $4(1.6)$ & $4(2.0)$ & ns & \\
\hline$* 0606$ & 0 & $1(0.5)$ & ns & \\
\hline
\end{tabular}

Appendix: P value was determined by $\chi^{2}$ test comparing SLE group to controls, Puc. $=$ uncorrected $\mathrm{Pc} .=$ corrected with Bonferroni correction for 18 detected alleles, $\mathrm{n}=$ number of cases, $\mathrm{OR}=\mathrm{odds}$ ratio, $\mathrm{CI}=95 \%$ confidence interval 
3.

Allele Frequencies of the MICA TM exon 5 microsatellite polymorphism

and -1149 G/T SNP of the Extrapituitary Prolactin Promoter in patients with Systemic Lupus

Erythematosus (SLE) and healthy population (Controls)

\begin{tabular}{|c|c|c|c|c|}
\hline $\begin{array}{l}\text { Allele of the } \\
\text { microsatellite } \\
\text { exon } 5 \text { TM } \\
\text { polymorphism }\end{array}$ & $\begin{array}{c}\text { SLE } \\
2 \mathrm{n}=246(\%)\end{array}$ & Controls 2n=198 $(\%)$ & Pc. & OR $(95 \% \mathrm{CI})$ \\
\hline A4 & $26(10.6)$ & $25(12.6)$ & ns & \\
\hline A5 & $24(9.7)$ & $25(12.6)$ & ns & \\
\hline A5.1 & 137 (55.7) & $79(39.9)$ & 0.005 & $1.88(1.29-2.77)$ \\
\hline A6 & $26(10.6)$ & $39(19.7)$ & 0.035 & $0.48(0.28-0.82)$ \\
\hline A9 & $33(13.4)$ & $30(15.2)$ & $\mathrm{ns}$ & \\
\hline \multicolumn{5}{|l|}{$\begin{array}{l}\text { Allele of the } \\
-1149 \text { G/T } \\
\text { SNP PRL }\end{array}$} \\
\hline $\mathbf{G}$ & $142(57.7)$ & $112(56.7)$ & ns & \\
\hline $\mathbf{T}$ & $104(42.3)$ & $86(43.3)$ & $\mathrm{ns}$ & \\
\hline
\end{tabular}

Appendix: P value was determined by $\chi^{2}$ test comparing SLE group to controls, Pc.=corrected with Bonferroni correction for 5 detected alleles, $n=$ number of cases, $\mathrm{OR}=$ odds ratio, $\mathrm{CI}=95 \%$ confidence interval 